\title{
Endoscopic management of difficult bile duct stones
}

CHRISTIAN ELL, MD

C ELL. Endoscopic management of difficult bile duct stones. Can J Gastroenterol 1992;6(6):323-328. More than 90\% of all common bile duct concrements can be removed via the endoscopic retrograde route via endoscopic sphincterotomy, stone extraction by baskets and balloon catheters, or mechanical lithotripsy. Oversized, very hard or impacted stones, however, often still resist conventional endoscopic therapy. Promising new or improved approaches for the treatment of these stones are intracorporeal or extracorporeal shockwave lithotripsy. Shockwave lithotriptors for extracorporeal shockwave lithotripsy are currently available worldwide. However, for the waterbath first generation devices, general anesthesia is required since shockwaves are very painful. Furthermore, an x-ray localization system is essential to visualize the stones after having filled the bile duct over a nasobiliary catheter. An average of two shockwave treatments with additional two to four endoscopic sessions are required. Intracorporeal lithotripsy promises more comfort and less effort for the patient. Shockwaves are generated either by means of the spark gap principle (electrohydraulic probes) or by laser-induced plasma generation. Laser-induced shockwave lithotripsy appears to be more safer, since with dye and solid state lasers, athermal, well-controlled shockwaves can be generated without the risks for duct perforation (as described for the electrohydraulic system). Furthermore, a recently developed stone-tissue detection system integrated in a new dye laser system enchances the safety of laser-induced lithotripsy. In consequence, lithotripsy without direct endoscopic control appears possible in selected cases.

Key Words: Bile duct stones, Extracorporeal shockwave lithotripsy, Gallstones, Laser, Lithotripsy

\section{Traitement par voie endoscopique de la lithiase difficile du cholédoque}

L'exérèse de plus de $90 \%$ de tous les calculs biliaires communs peut se faire par voie endoscopique au moyen d'une sphinctérotomie endoscopique rétrograde, par des cathéters ou par lithotritie mécanique. Cependant, les calculs de fortes dimensions, très durs ou enclavés, résistent encore souvent au traitement endoscopique classique. Parmi les nouvelles approches prometteuses dans le traitement de ces calculs, se trouve la lithotritie intra- ou extra-corporelle par ondes de choc.

Department of Medicine, Friedrich-Alexander-University Erlangen-Nuremberg, Germany Correspondence and reprints: Dr Christian Ell, Department of Medicine, Krankenhausstr.

12, Friedrich-Alexander-University Erlangen-Nuremberg, D-8520 Enlangen, Germany
OINCE The InTROduction OF ENDODemling and Classen $(1,2)$ in Erlangen and, almost simultaneously, by a Japanese group centred around Kawai (3), it has become possible to remove about $80 \%$ of all common bile duct stones via the endoscopic retrograde route. The endoscopic technique, with its overall complication rate of 5 to $10 \%$ and a method-related mortality rate between 0.5 and $1 \%$, is safer than surgical intervention $(4,5)$. If one is dealing with concrements that are too large to be extracted by means of a conventional basket or a ballon catheter, mechanical lithotripsy represents a valuable supplementary option in endoscopic therapy (6). The experiences reported for the different types of mechanical lithotripters are positive in varying degrees (7). Nonetheless, it can be stated that stones greater than $2 \mathrm{~cm}$ in diameter are often difficult to fragment mechanically; they can either not be grasped by the lithotripter basket, or the lithotripter does not exert sufficient force to achieve mechanical disintegration $(5,8)$. Mechanical lithotripsy is low in cost and free from severe complications which accounts for its current widespread use and increasing popularity.

If giant stones, very hard or impacted concrements are lodged in the bile duct, conventional endoscopic meth- 
Les lithotriteurs par ondes de choc sont maintenant disponibles partout au monde. Avec les appareils de première génération l'anesthésie générale est nécessaire, puisque les ondes de choc sont très douloureuses. En outre, un système de localisation par rayons $\mathrm{X}$ est essentiel pour visualiser les calculs après avoir investi les voies biliaires avec un cathéter naso-biliaire. Il faut en moyenne deux traitements par ondes de choc et de deux à quatre séances endoscopiques additionnelles. La lithotritie intra-corporelle s'annonce plus confortable et moins exigeante pour le patient. Les ondes de choc sont générées soit à l'aide du principe des sondes électrohydrauliques, ou par génération plasmatique au laser. La lithotritie par ondes de choc au laser semble plus sûre, puisqu'avec les colorants et les lasers, on parvient à produire des ondes de choc athermiques bien contrôlées, sans risque de perforer les voies biliaires (selon la description du système électrohydraulique). En outre, un système de détection des calculs récemment développé s'associe à un nouveau système de laser à colorant qui rend plus sécuritaire la lithotritie au laser, de sorte que la lithotritie sans contrôle endoscopique direct semble possible dans certains cas.

\section{TABLE}

\section{Therapeutic options for difficult common bile duct stones}

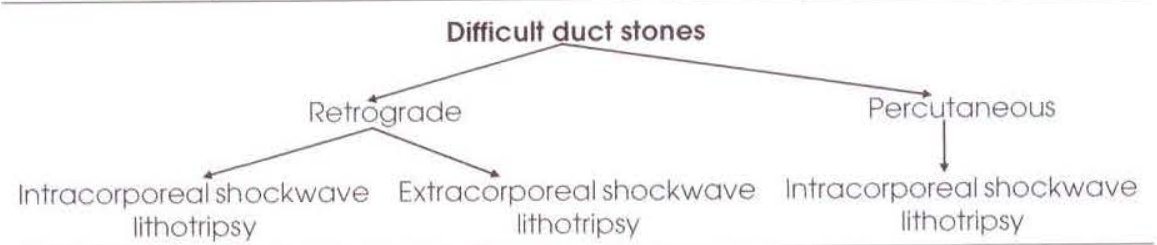

ods may fail, thus necessitating treatment by intra- or extracorporeal lithotripsy techniques. If the papilla cannot be reached endoscopically (eg, Bll-stomach) or if the stone is lodged proximal to the bile duct stricture and cannot be acceded via the endoscopic retrograde route, a percutaneous transhepatic approach to the stone has to be chosen (Table 1).

\section{RETROGRADE APPROACH}

A sphincterotomy which is as wide as possible represents an unconditional prerequisite for any form of endoscopic therapy of large concrements in the bile duct. For technical reasons intracorporeal lithotripsy (electrohydraulic, laserinduced) without direct endoscopic visual control has been confined to individual case studies to date (9). Similarly at the outset in the field of intracorporeal lithotripsy performed with direct endoscopic monitoring, only unstable mother-babyscope prototype systems susceptible to damage were available at the time. The babyscope with a $4.5 \mathrm{~mm}$ outer diameter and a $1.7 \mathrm{~mm}$ instrumentation channel has in the meantime proven its overall reliability and durability. Its optical quality is also good. Prototypes with a $3.4 \mathrm{~mm}$ babyscope which can be introduced via a standard treatment instrument with correspondingly reduced dimensions promise an improved handling capability and greater flexibility. The $1.2 \mathrm{~mm}$ instrumentation channel integrated in this prototype is adequate at least as far as laser lithotripsy applications are concerned. The introduction of the babyscope in the common bile duct can be conducted directly via the mother instrument or by means of a previously inserted guidewire (in order to protect the babyscope).

Nasobiliary catheters serving to achieve sufficient instillation of water are imperative for electrohydaulic intracorporeal lithotripsy, and facilitate both laser-induced lithotripsy and extracorporeal shockwave lithotripsy. At the same time they ensure bile flow under any circumstances and provide protection against cholangitis. The question whether perioperative prophylactic treatment with antibiotics is advisable and necessary during intra- ductal lithotripsy cannot as yet be conclusively answered.

\section{TRANSHEPATIC APPROACH}

The transhepatic approach should only be considered if the possibility of performing lithotripsy and fragment $\mathrm{ex}$ traction via the retrograde route does not appear to be given. Additional risks are involved in the latter case. Various techniques of bile duct punction and bougienage to create a sinus tract have been described $(10,11)$. Basically, a distinction has to be made between the single step procedure and sequential bougienage spanning a period of over one to two weeks. The risk of bleeding appears to be lower in the sequential procedure $(10,11)$. Flexible cholangioscopes with an outer diameter between 3.2 and $5.0 \mathrm{~mm}$ are used for percutaneous endoscopy. In principle, electrohydraulic and laser-induced lithotripsy can both be applied transhepatically. Following stone disintegration, the fragments are extracted by using a small basket or are pushed through the papilla into the small intestine. Antegrade papillotomy via the transhepatic route has been performed only in a select number of cases to date. Extracorporeal lithotripsy: Three basic physical principles are presently being used for shockwave generation in extracorporeal shockwave lithotripsy; electrohydraulic generation was the original principle whereas the newer methods are based on piezoelectric and electromagnetic principles. At present, second-and third-generation shockwave systems are available which are capable of attaining virtually equivalent fragmentation efficacies (12). A decisive advantage offered by the piezoelectric shockwave system - which advocates its clinical application - is that it can be applied with distinctly less pain compared with the other two types of systems (13), a finding substantiated by a triple centre study on volunteers (14). Stone localization generally is performed by $\mathrm{x}$-ray or ultrasound techniques (15). Both forms of localization are currently supported by sufficient data. Nevertheless, there is no doubt that ultrasound localization of bile duct stones requires a great deal more time 
than $x$-ray localization. Insertion of a nasobiliary catheter proved helpful in sonographic localization since, for one, echo-generating aerocholy in the bile duct system can be avoided by continuous infusion of saline and, secondly, the sonographic double structure of the catheter can serve as a helpful orientation. When x-ray localization is employed, contrast agent is instilled via an indwelling nasobiliary probe (Figure 1). The nasobiliary catheterr should have holes only at its tip to ensure that the contrast agent effuses proximal to (or at least in the immediate vicinity of) the concrements and does not flow into the intestine prematurely. Nasobiliary catheters featuring a balloon to prevent discharge of contrast agent into the intestine are also helpful. Several reports do exist which maintain that extracorporeal shockwave lithotripsy can be performed without preceding papillotomy; however, since the risk of a biliary pancreatitis cannot be ascertained reliably in the latter case, this procedure generally should be avoided. The success rate assigned to extracorporeal shockwave lithotripsy of stones which cannot be treated endoscopically is up to $80 \%$ (15). Especially in the case of bile ducts completely filled with concrements, shockwave lithotripsy proves less successful. A number of shockwave sessions often have to be carried out with subsequent clearance of fragments by endoscopy. On the whole, the stress imposed on the patient and the risk of complications associated with extracorporeal shockwave lithotripsy must be rated as generally low, considering the high risk patient group. Whereas general anesthesia was still required at the outset of shockwave lithotripsy, sedation-analgesia is sufficient for all systems at present, and when using the piezoelectric principle, analgesics or sedatives frequently are unnecessary. The main risk is the danger of a cholangitis-extracorporeal lithotripsy, therefore, should always be performed using an indwelling nasobiliary catheter. One must be aware of the substantial material and personnel investment involved, as normally every patient requires several endoscopic as well as shockwave sessions.



Figure 1) Common bile duct with a large stone prior to (right), immediately after (centre) and one day after (left) extracorporeal shockwave lithotripsy

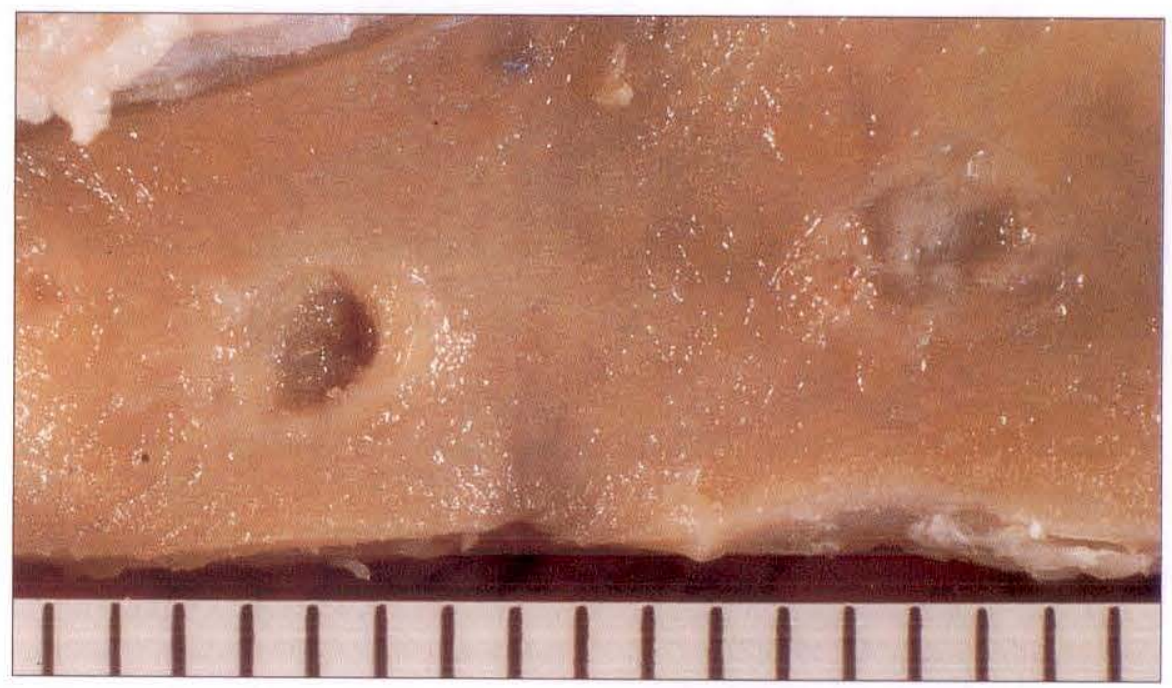

Figure 2) Perforation of the common bile duct of a rabbit after one pulse by means of a electrohydraulic probe directed to the wall

Intracorporeal shockwave lithotripsy: The first clinical applications of intracorporeal electrohydraulic shockwave lithotripsy in the biliary duct were conducted without direct endoscopic visual control (9). The system-inherent risks of wall perforation, however, soon put an end to these purely radiologically monitored applications. Electrohydraulic lithotripsy, which was directly monitored by endoscopy, thus remained restricted to a small group of cases (16-18), If one disregards the problems involved in fine calibre endoscopy at the time, the probe diameter and its limited degree of flexibility represented a major obstacle to applying this method (which proved highly effective in terms of fragmentation efficacy). The risk of wall perforation remained unchanged even after continued technical development of electrohydraulic lithotripsy gave rise to thinner and more flexible lithotripsy probes. A number of in vitro and animal studies showed that wall perforations must be taken into account even at intensity levels which do not as yet provide a sufficient degree of stone fragmentation (19) (Figure 2). With one exception (11), publications covering larger patient groups treated by the electrohydraulic intracorporeal lithotripsy technique are not available to date. 
TABLE 2

Physical features of different pulsed laser systems

\begin{tabular}{llll}
\hline & $\begin{array}{l}\text { Q-switched } \\
\text { Nd:YAG laser }\end{array}$ & Alexandrit & Dye \\
\hline Type & Solid state & Solid state & Dye \\
Wavelength & $1064 \mathrm{~nm}$ & 750 to $800 \mathrm{~nm}$ & 500 to $600 \mathrm{~nm}$ \\
Pulse length & 5 to $20 \mathrm{~ns}$ & 359 to $500 \mathrm{~nm}$ & 1 to $3 \mu \mathrm{m}$ \\
Pulse energy & 10 to $25 \mathrm{~mJ}$ & 40 to $80 \mathrm{~mJ}$ & 40 to $120 \mathrm{~mJ}$ \\
\hline
\end{tabular}

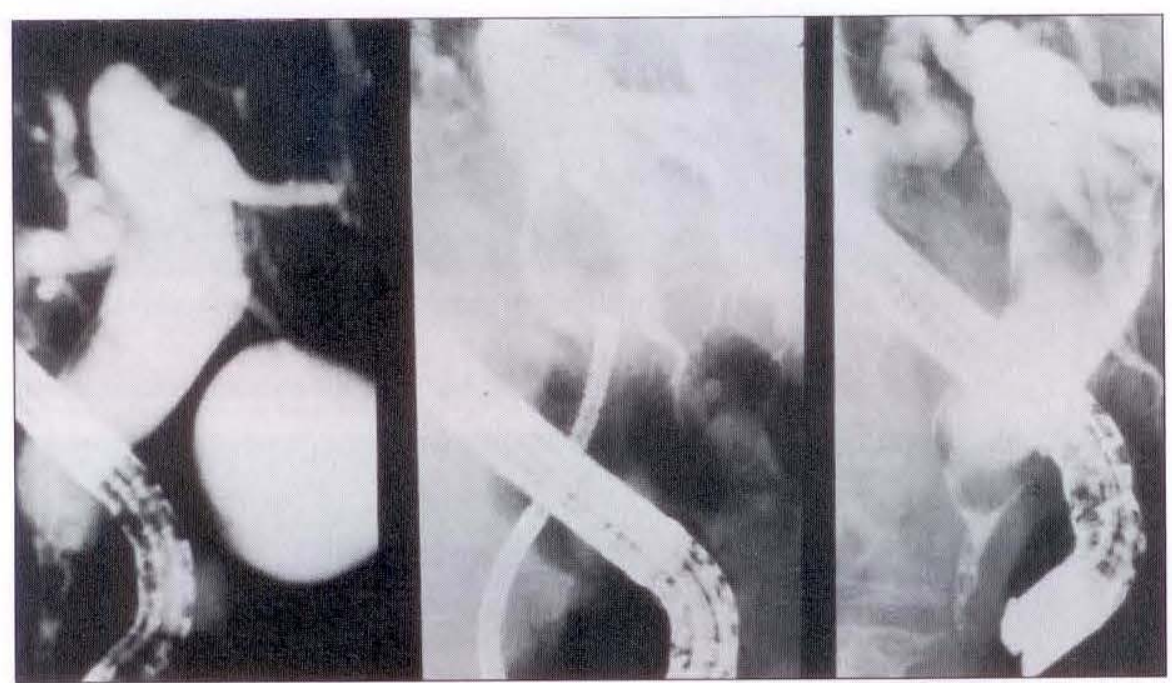

Figure 3) Laser induced lithotripsy via the mother-babyscope prior to (right) during (centre) and after (left) clearance of the duct

However, personal communications forwarded by two German research groups, which each treated about 40 patients suffering from large stones in the biliary duct by means of electrohydraulic lithotripsy, speak in favour of the technique being applied with a high degree of safety when in the hands of an experienced operator and complemented by direct endoscopic control. Nonetheless, continual rinsing of the biliary duct with saline via a nasobiliary catheter remains a necessary precondition for such applications, as shockwaves can be induced electrohydraulically only if sufficient fluid is present and continuous rinsing leads to a clearer view. However, because a precise overview can frequently not be maintained after the first shockwave pulse, this method should be employed only in centres with a great deal of experience and expertise in motherbabyscopy.

Laser-induced lithotripsy: The first steps in laser-induced lithotripsy led from the continuous wave Nd:YAG laser to pulsed Nd:YAG lasers with a long pulse duration (20); the use of short $\mathrm{Nd}$ :YAG laser pulses (in the nanosecond range) may be seen as the third step leading to athermal, purely mechanical laser-induced shockwave lithotripsy $(21,22)$. Although it has become possible to transmit and intracorporeally apply nanosecond pulses with peak power values of up to $1,000,000 \mathrm{~W}$ via highly flexible optical fibres with a thickness of $300 \mu \mathrm{m}(21,23)$, this laser system is still in the prototype stage.

Currently, the flash lamp pulsed dye laser systems are most widespread in clinical applications. Organic dyes (mostly dissolved in alcohol) are used as the active laser material. Depending on the type of dye used, the wavelength covers a range from 500 to $600 \mathrm{~nm}$ (Table 2). The pulse length varies between 1 and $3 \mu \mathrm{m}$. In contrast to the Q-switched Nd:YAG laser which does not give rise to significant damage to tissue, this measure of safety in application is not applied to the same extent in the case of the dye laser $(22,24-26)$. Despite the fact that when applying the flash lamp pulsed dye laser, the plasmadriven fragmentation is a thermal process after the plasma has been ignited, the occurrence of bile duct perforation within a couple of seconds has been reported in vitro and in animal experiments; in such cases the relatively high light absorption of hemoglobin in the wavelength region of 500 to 600 $\mathrm{nm}$, as opposed to the wavelength region around $750 \mathrm{~nm}$, with only minimal absorption by hemoglobin, appears to play a major role in determining the risk of tissue destruction when dye lasers are applied. From the studies reported in the literature and based on the author's results obtained from animal experiments concerning the tissue hazards observed when applying the dye laser, flash lamp pulsed dye laser applications should be carried out only under direct endoscopic control, even if the risk of complications can be regarded as lower than in the case of the electrohydraulic principle (Figure 3).

Reports on larger case figures have also become available for dye laser systems (27,28). Confirming that applications under direct endoscopic control are safe and effective. This holds true for retrograde applications and, to a greater degree, for transhepatic procedures because the approach to the stone is easier and better.

With the development of the alexandrite laser for clinical applications in gastroenterology, an attempt has been made to achieve the fragmentation performance of the dye laser by using a solid state laser while foregoing the risk of significant damage to tissue. The currently available alexandrite lasers are indeed capable of fragmenting gallstones. The hazard of damaging tissue via faulty application thereby remains relatively low (unpublished data). The latest development in the field of laser lithotripsy is the stone tissue detection system which is integrated in the laser lithotripter. The first investigations conducted by the authors' group to test the suitability of this system for biliary duct applications have confirmed the system's ability to distinguish between stones and tissue with a high degree of precision (found not only in in vitro investigations, but also in animal ex- 
periments [29]). The first practical clinical experience gained with this system (Lithognost, Telemit; Munich, Germany) confirmed the efficacy of therapy, on one hand, and the reliability with which the system discriminates between stones and tissue on the other hand (unpublished data).

The integrated stone-tissue discrimination capability of the system opens up a number of perspectives in laser-induced lithotripsy: first - as successfully performed demonstrated in individual cases - the option of an exclusively radiologic controlled intracorporeal laser lithotripsy becomes feasible, leading to financial and technical advantages (eg, a standard endoscope could be used instead of a mother-babyscope). The substitution of mechanical lithotripsy in a large proportion of cases by laser techniques could be envisaged once a laser lithotripsy system which is easy to handle and safer becomes readily available. The fact that the laser is able to achieve a very fine fragmentation may eliminate (in selected cases) endoscopic papillotomy the part of

\section{REFERENCES}

1. Demling L. Operative Endoskopie. Med Welt 1973;24:1253.

2. Classen M, Demling L. Endoskopische Sphinkterotomie der Papilla Vateri und Steinextraktion aus dem Ductus choledochus. Dtsch Med Wschr 1974:99:496.

3. Kawai KY, Akasaka K, Murakami M. Endoscopic sphincterotomy of the papilla of water. Gastrointest Endosc 1974:20:148-50.

4. Ell C. Endoskopische Entfernung von Gallengangsteinen. Verh Dtsch Ges Innere Med 1988;94:112.

5. Classen M, Hagenmüller F, Knyrim K, Frimberger E. Giant common bile duct stones-non-surgical treatment. Endoscopy 1988;20:21-6.

6. Demling L, Seuberth K, Riemann JF. A mechanical lithotripter. Endoscopy 1982;14:100.

7. Schneider MU, Matek W, Bauer R, Domschke W. Mechanical lithotripsy of common bile duct stones in 209 patients: Effect of technical advances. Endoscopy 1988;20:248.

8. Liguoury C, Lefebvre JF, Bonnel D, et al. Lithotritie mécanique des calculs de la voie biliaire principale. Chirurgic 1987;1 1 3:556-61.

9. Koch H, Rösch W, Walz V. Endoscopic lithotripsy in the bile duct. endoscopic stone therapy posing the greatest risk.

\section{CLINICAL STRATEGY}

Endoscopic papillotomy with stone extraction will remain the standard clinical strategy. Mechanical lithotripsy will also assert its present importance in the immediate future. If a concrement cannot be removed by this method, intracorporeal lithotripsy techniques, according to availability, will be the most reasonable methods of choice; in the hands of an experienced operator and when performed under direct endoscopic visual control, intracorporeal electrohydraulic lithotripsy appears to be effective and sufficiently safe. Laser-induced lithotripsy offers a greater safety potential while maintaining a similar level of efficiency, especially if a laser with a stone-tissue discrimination system is used. Solid state lasers in the 750 to $1100 \mathrm{~nm}$ wavelength region can also contribute to minimizing risks. In combination with the conventional endoscopic techniques, extracorporeal shockwave

Gastrointest Endoscopy 1980;26:16.

10. Yamakawa T. Percutaneous cholangioscopy for management of retained biliary tract stones and intrahepatic stones. Endoscopy 1989;21:333-8.

11. Bonnel DH, Ligoury CE, Cornud FE, Lefebvre JP. Common bile duct and intrahepatic stones: Results of transhepatic electrohydraulic lithotripsy in 50 patients. Radiology 1991;180:345-8.

12. Schneider HT, Fromm M, Janowitz P et al. In vitro fragmentation of gallstones:Comparison of electrohydraulic, electromagnetic and piezoelectric shockwave lithotripters. Hepatology 1991;14:301.

13. Ell C, Schneider HT, Benninger ], et al. Significance of computed tomography for shockwave therapy of radiolucent gallbladder stones. Gastroenterology 1991;101:1409-16.

14. Schneider HT, Hummel T, Janowitz P, et al. Pain in extracorporeal shockwave lithotripsy: A comparison of different lithotripters in volunteers. Gastroenterology. (In press)

15. Sauerbruch T, Stern M. Fragmentation of bile duct stones by extracorporeal shock waves. Gastroenterology 1989;06:146.

16. Tanaka M, Yoshimoto H, Ideka S, lithotripsy represents a valuable and efficient addition to nonsurgical stone therapy. Depending on availability, the technique should be employed specifically when implementation of intracorporeal lithotripsy methods is not possible or remains without success. If laser lithotripsy can, in the future, be carried out with conventional endoscopes without the need for endoscopic monitoring, the development trend towards intracorporeal lithotripsy will gain further momentum.

The transhepatic endoscopic approach using intracorporeal laser or electrohydraulic lithotripsy should only be chosen if the stone cannot be acceded by the retrograde route. Depending on the experience of the operator and the employed technology, a partly substantial additional risk of complications must be taken into account. Nonetheless, transhepatic endoscopically controlled lithotripsy represents a technique with a substantial clinical potential for the future. Hepaticolithiasis can thus be expected to become a domain of nonsurgical transhepatic lithotripsy.

Matsumoto S, Xuan GR. Two approaches for electro-hydraulic lithotripsy in the common bile duct. Surgery 1985;98:313-8.

17. Lear JL, Ring EA, Macoviak JA, Baum S. Percutaneous transhepatic electrohydraulic lithotripsy. Radiology 1984;150:589-90.

18. Liguory C, Bonnel D, Canard JM, Cornud F, Dumont JL. Intracorporeal electrohydraulic shock wave lithotripsy of common bile duct stones:Preliminary results in seven cases. Endoscopy 1987;19:237-40.

19. Hochberger J, Wisbacher R, Gruber E, Hahn EG, Ell C. Laser-versus elektrohydraulische Lithotripsie zur Fragmentation von Gallengangssteinen? Ergebnisse zu Fragmentation und Gewebeschddigung 'in vitro' und 'in vivo'. Klin Wschr 1991;69:S 30.

20. Ell C, Lux G, Hochberger J, Müller D, Demling L. Laserlithotripsy of common bile duct stones. Gut 1988;29:746-51.

21. Hochberger J, Gruber E, Wirth P, et al. Lithotripsy of gallstones by means of a Q-switched giant pulse Nd:YAG laser: Basic in vitro studies using a highly flexible fiber system. Gastroenterology 1991;101:1391-8.

22. Watson G, Dretier SP, Parrish ]. The pulsed dye laser for fragmenting urinary calculi. J Urol 1987;138:195. 
23. Weißmüller 1, Schatfhauser W, Schroff KM, Hochberger J, Ell C. Laserlithotripsie von Harnleitersteinen. Urologie A 1991;30:333-6.

24. Nishioka NS, Teng P, Deutsch TF, Anderson R. Mechanism of laserinduced fragmentation of urinary and biliary calculi. Lasers Life Sci 1987;8:231-45.

25. Teng P, Nishioka S, Farinelli W, Anderson R, Deutsch T.
Microsecond-long flash photography of laser-induced ablation of biliary and urinary calculi. Lasers Surg Med 1987:7:394-7.

26. Nishioka N, Kelsey P, Kibbi A, Delmonico F, Parrish J, Anderson R. Laser lithotripsy: Animal studies of safety and efficacy. Lasers Surg Med 1988;8:357-63.

27. Cotton PB, Kozarek RA, Schapiro RH, et al. Endoscopic laser lithotripsy of large bile duct stones. Gastro- enterology 1990;99:1128-33.

28. Ponchon T, Gagnon P, Valette PJ, Henry L, Chavaillon A, Thieulin F. Pulsed dye laser-lithotripsy of bile duct stones. Gastroenterology 1991;100:1730-6.

29. Hochberger J, Hahn EG, Ell C. Stone-tissue detection system for laser-induced lithotripsy. In vitro and animal experiments.

Gastroenterology 1992;102:315. 


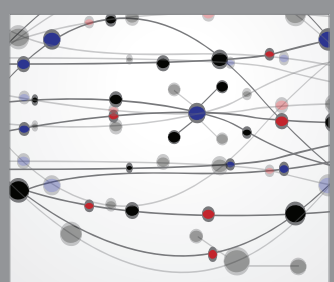

The Scientific World Journal
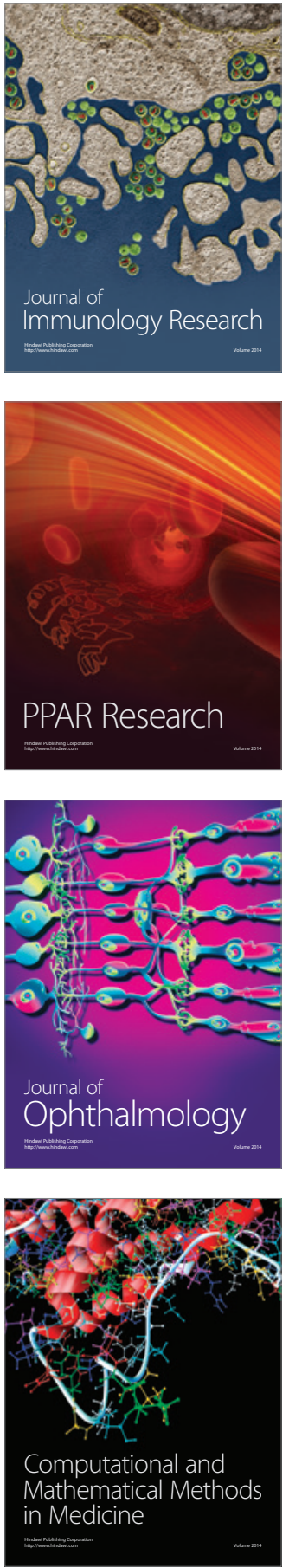

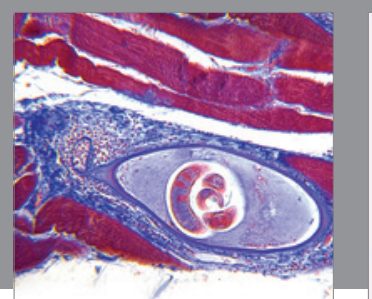

Gastroenterology Research and Practice

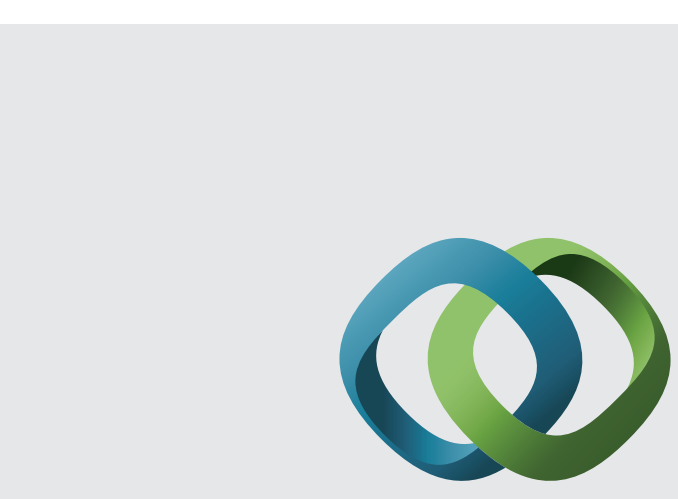

\section{Hindawi}

Submit your manuscripts at

http://www.hindawi.com
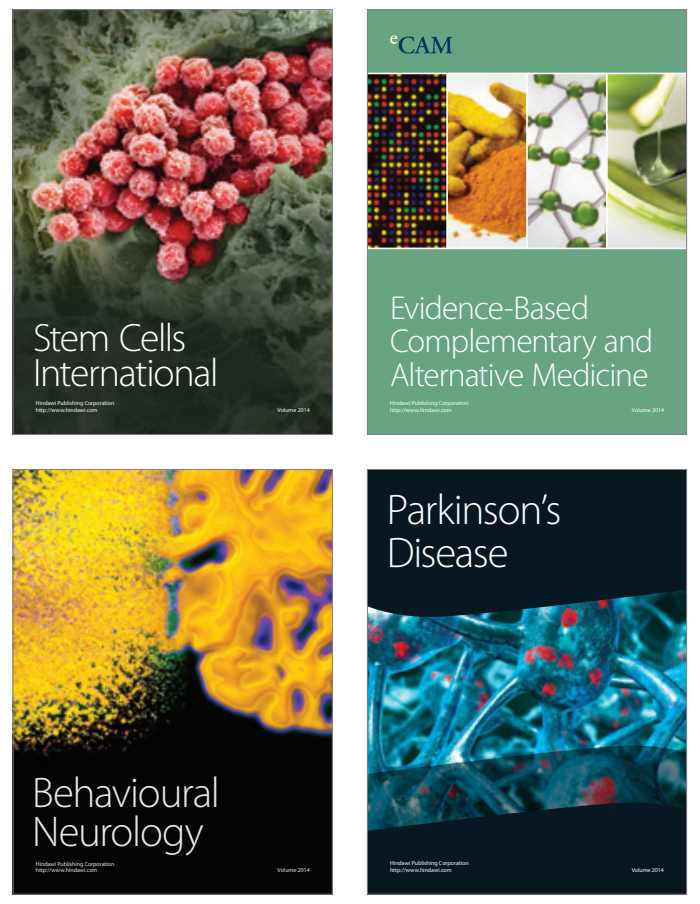
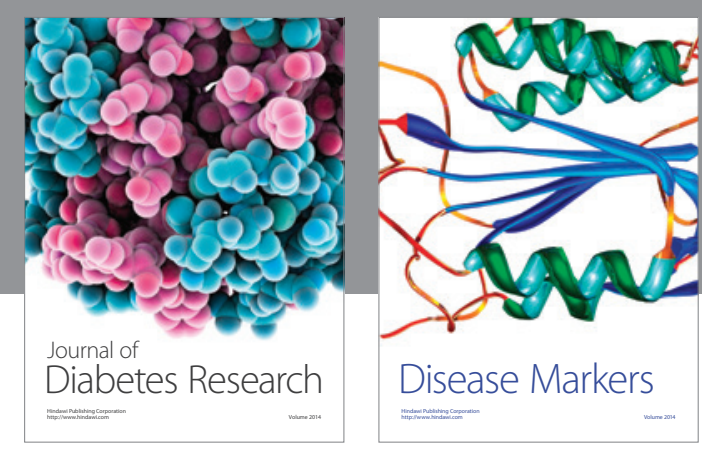

Disease Markers
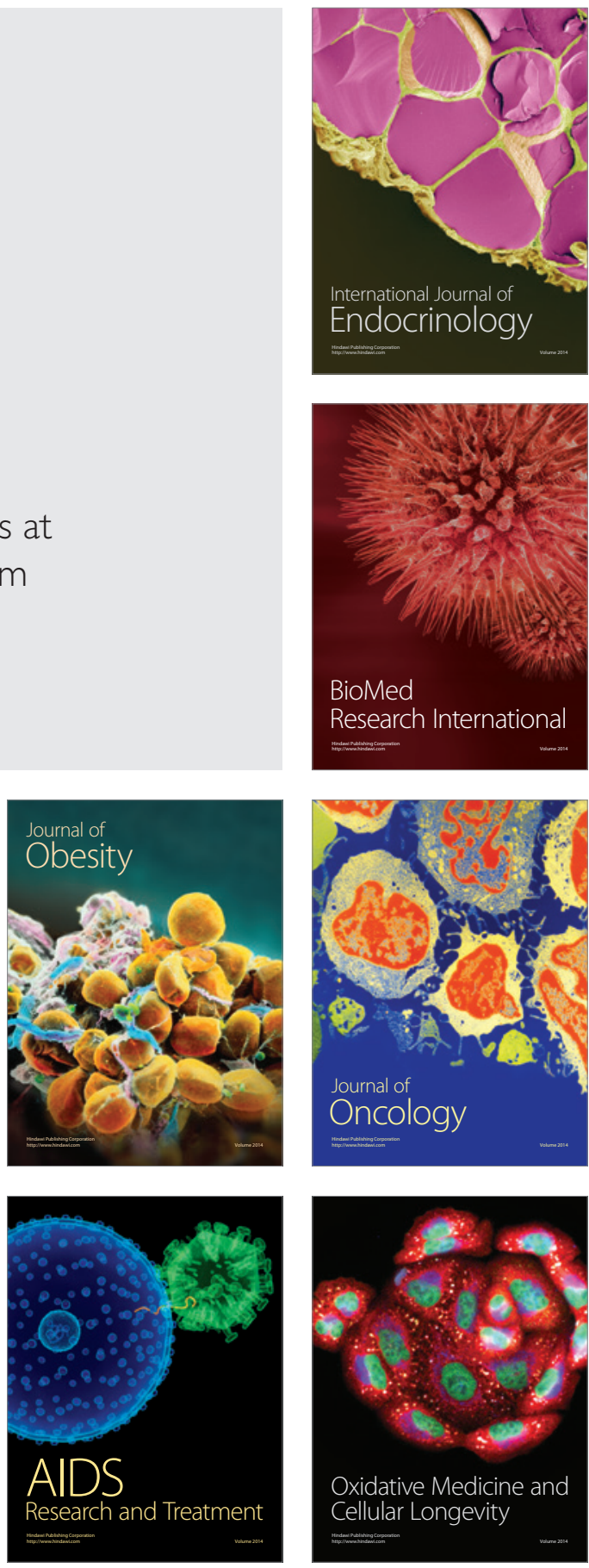